\title{
PERSPECTIVAS AMBIENTAIS
}

Márcia Souza De Aguiar ${ }^{1}$

Resumo

A sustentabilidade ambiental traz um novo direcionamento às empresas ao mudar estratégias e métodos de produção. Isso significa mudanças de concepção para usufruir de forma consciente as possibilidades que o meio ambiente oferece. Este artigo tem por objetivo apresentar propostas de novos posicionamentos que podem trazer alternativas para melhorar a competitividade em contexto ambiental. Destacam-se a inovação ambiental, estratégia, tecnologia e atuação do Estado. Foram utilizadas pesquisas bibliográficas para atingir os objetivos deste texto. Conclui-se que a busca de vantagens competitivas pelas empresas através de um direcionamento estratégico e da dinâmica das inovações podem trazer oportunidades ainda não exploradas com o advento da questão ambiental.

Palavras-chave: Competitividade. Inovação Ambiental. Mudança de Paradigma.

\begin{abstract}
Environmental sustainability brings a new direction to the companies to change strategies and productions methods. This means changes in design for use in a conscious way the possibilities that the environment offers. This article aims to present proposals for new positions that can bring alternatives to improve the competitiveness in the environmental context. Of particular note are the environmental innovation, strategy, technology and expertise of the State. Bibliographic research were used to achieve the objectives of this text. It is concluded that the pursuit of competitive advantages for businesses through a strategic direction and dynamics of innovation can bring opportunities not yet explored with the advent of environmental issue.
\end{abstract}

Keyword: Competitiveness. Environmental Innovation. Change of Paradigm.

Área ABEIN: Área 6 - Inovação, Desenvolvimento e Sustentabilidade.

Classificação JEL: O39; Q55.

\footnotetext{
${ }^{1}$ Mestranda em Desenvolvimento Econômico, Espaço e Meio Ambiente - IE/UNICAMP, SP.
} 


\section{PERSPECTIVAS AMBIENTAIS}

\section{Resumo}

A sustentabilidade ambiental traz um novo direcionamento às empresas ao mudar estratégias e métodos de produção. Isso significa mudanças de concepção para usufruir de forma consciente as possibilidades que o meio ambiente oferece. Este artigo tem por objetivo apresentar propostas de novos posicionamentos que podem trazer alternativas para melhorar a competitividade em contexto ambiental. Destacam-se a inovação ambiental, estratégia, tecnologia e atuação do Estado. Foram utilizadas pesquisas bibliográficas para atingir os objetivos deste texto. Conclui-se que a busca de vantagens competitivas pelas empresas através de um direcionamento estratégico e da dinâmica das inovações podem trazer oportunidades ainda não exploradas com o advento da questão ambiental.

Palavras-chave: Competitividade. Inovação Ambiental. Mudança de Paradigma.

\section{Introdução}

A valorização de questões ambientais vem através das décadas motivando diversos estudos relatando a necessidade da inclusão de variáveis socioambientais no desenvolvimento econômico para além do PIB. Pressão de diversos grupos, tecnologia da informação e comunicação mais eficazes, surgimento de organizações da sociedade civil e expansão de diversos negócios com características de melhor aproveitamento dos recursos naturais fizeram a evolução do capitalismo presenciar uma valorização por parte do mercado da responsabilidade socioambiental das corporações. O desafio de valorizar e integrar a sustentabilidade às estratégias corporativas trouxe mudanças significativas na produção e na gestão de diversas empresas. A relevância da análise dos impactos de critérios sociais e ambientais se torna mais criteriosa, pois novos paradigmas podem ser estimulados a partir da prioridade ambiental. Para tanto, as motivações empresarias se tornam complexas à medida que, de acordo com o padrão institucional, tenta-se unir performance financeira e ambiental e resultar em ações estratégicas que justifiquem as práticas sustentáveis e sociais.

De acordo com as considerações acima o objetivo deste trabalho consiste em, a partir de análise bibliográfica, responder à seguinte indagação: Quais são as perspectivas para um melhor aproveitamento da sustentabilidade ambiental nos negócios?

Esse estudo é justificado pelo fato de que os processos de inovação e direcionamento ambientais podem fortalecer a concorrência capitalista, em diversos níveis (geral, mercado, política), e usar a tecnologia como fator positivo no meio ambiente.

O cenário atual, onde várias empresas redefinem suas estratégias integrando os princípios de sustentabilidade, considerando os diferentes interesses dos atores envolvidos e principalmente os impactos causados pelos agentes ao meio ambiente, provocou uma mudança sensível em diversas instituições incluindo países, alterando atividades e se difundindo por toda a atividade econômica.

Propiciar a criação ou o reposicionamento em novos mercados e responsabilizar-se pelos impactos ambientais em todo o ciclo de vida do produto são estratégias que Epelbaum (2004) afirma que as empresas podem adotar.

Neto et al.(2011,p.11) apresentam duas linhas de raciocínio no que refere ao hiato entre fator econômico e fator ambiental: a primeira, “na perspectiva tradicionalista, há um conflito claro de interesses entre o entendimento das benesses e da urgência da questão ecológica e seu 
discurso preservacionista e o do excesso de regulação tornar-se elemento de atraso nos níveis produtivos". A segunda diz respeito ao "amadurecimento do conflito de interesses que tem apontado para o uso da inovação e da criatividade como saídas inteligentes para conciliar posições à primeira vista díspares”.

O mesmo autor reforça que algumas organizações mesmo não atuando em mercado com produtos ecológicos, conseguem aliar ótimos resultados financeiros às estratégias de gestão ambiental, graças a tomadas de decisão criativas e inovadoras onde pressão do mercado e regulações são encaradas como oportunidades e não como ameaças.

Salviano (2004) acorda que o enfoque deve ser a elevação da produtividade dos recursos e como estratégias ambientais a participação da alta gerência é um imperativo, pois se trata de aumento de competitividade.

Freeman (1992 apud Reydon;Cavini;Escobar;Faria,2007) informa que no ambiente seletivo em que ocorrem as mudanças técnicas, empresas em competição se coadunam com esforços científicos e tecnológicos internos e às políticas públicas, considerando que um paradigma técnico-econômico (não evolui sozinho) é dirigido por atores e instituições econômicas e sociais.

Barbosa (2007) sugere que a inovação seja fundamental para a integração da gestão ambiental à estratégia da empresa, pois reduzem o custo total do produto e aumentam a produtividade o que permite reduzir o desperdício, as emissões e a geração de resíduos.

Santos e Finazzi (2008,p.1) complementam:

\begin{abstract}
As riquezas naturais, esvaziadas do seu real valor de uso, durante gerações, assumiram papel de destaque no mercado financeiro. Justamente o segmento que as desdenhava a simples recursos de troca constatou que sua gestão integrada às estratégias empresariais, oferece oportunidades de sustentabilidade para os seus negócios.
\end{abstract}

\title{
1-Contexto Ambiental
}

As discussões em torno de questões ambientais vêm progredindo desde o final do século passado sobre impactos causados pela produção de bens e serviços. No início, as condições impostas por legislações condicionavam as mudanças para a proteção do meio ambiente; hoje o uso racional dos recursos e principalmente as estratégias e o desempenho das firmas diante dessas questões se tornam visivelmente relevantes, pois a importância de uma eficiente gestão ambiental contribui de forma decisiva para a imagem e a produtividade de empresas e de países.

Segundo Demajorovic (2003) da Revolução Industrial até 1950, os problemas ambientais eram compreendidos de forma isolada e reduzidos à poluição dos rios e do ar. Cita-se como exemplo o rio Tâmisa na Inglaterra que foi recuperado e fazia parte de áreas bastante degradadas.

No quadro a seguir é sintetizada a evolução das principais abordagens ambientais e exemplificam a evolução das mudanças no comportamento dos países e das empresas por novas perspectivas possibilitando o aumento da produtividade do uso dos recursos naturais de forma a melhorar a competitividade nos negócios e considerar a busca por inovações: 


\begin{tabular}{|l|l|l|}
\hline Anos 1950/1960 & Anos 1970/1980 & Anos 1990/2000 \\
\hline $\begin{array}{l}\text {.Regulamentação mínima } \\
\text {.Enfoque limitado à água e ao } \\
\text { ar }\end{array}$ & $\begin{array}{l}\text {.Atitude reativa: } \\
\text { cumprimento das normas } \\
\text {.Sistemas de licenciamento } \\
\text { de indústrias e avaliação do } \\
\text { impacto ambiental }\end{array}$ & $\begin{array}{l}\text {.Atitude proativa: desempenho } \\
\text { superior às normas } \\
\text {.Códigos voluntários de } \\
\text { conduta e instrumentos } \\
\text { econômicos }\end{array}$ \\
\hline $\begin{array}{l}\text {.Reconhecimento mínimo } \\
\text { dos resíduos perigosos }\end{array}$ & $\begin{array}{l}\text {.Controle no final do } \\
\text { processo (End of pipe) } \\
\text {.Início das tecnologias } \\
\text { limpas }\end{array}$ & $\begin{array}{l}\text {.Adoção do ciclo de vida } \\
\text {.Produção mais limpa }\end{array}$ \\
\hline $\begin{array}{l}\text {.Inexistência de } \\
\text { responsabilidade corporativa }\end{array}$ & $\begin{array}{l}\text {.Responsabilidade } \\
\text { corporativa isolada }\end{array}$ & $\begin{array}{l}\text {.Integração total da } \\
\text { responsabilidade na estrutura } \\
\text { empresarial }\end{array}$ \\
\hline $\begin{array}{l}\text {.Meio ambiente 'livre' ou } \\
\text { 'quase livre’ (ênfase no } \\
\text { aumento da produção) }\end{array}$ & $\begin{array}{l}\text {.Início da internalização de } \\
\text { custos } \\
\text {.Regulamentação de multas } \\
\text { por danos ambientais }\end{array}$ & $\begin{array}{l}\text {.Contabilidade de custos } \\
\text { ambientais internos e externos }\end{array}$ \\
\hline
\end{tabular}

Fonte: Elaboração da autora com base em Ribeiro Neto;Tavares;Hoffmann,2010.

$\mathrm{Na}$ busca pelo desenvolvimento sustentável pode-se identificar o papel da microeconomia, pois conforme Portugal Jr.;Portugal (2010) o fator recursos naturais está sendo esgotado e, portanto, há a urgência de alteração no processo de produção que leve em conta a capacidade de carga do planeta. Os autores enumeram questões analíticas importantes como mensuração de custos e benefícios externos, valoração dos recursos naturais e do meio ambiente como bens, seja de propriedade privada ou pública, criação de regras e direitos de propriedade apropriada para os recursos ambientais e estabelecimento de normas para uso de recursos de propriedade comum e para provisão de bens públicos, balanço dos custos e benefícios através de alguma forma de análise custo/benefício na tomada de decisão.

Consequentemente, o conhecimento e a utilização de certos fundamentos microeconômicos (modelagem e análise microeconômica da teoria da empresa) ajudam as empresas nas decisões tomadas em contexto de racionalidade de mercado incluindo a variável meio ambiente.

Freeman (1992) defende que mesmo que um processo produtivo já tenha avançado ambientalmente, é necessário estender esse objetivo a todo o sistema econômico com o desenvolvimento de novas tecnologias. Para que um paradigma ambiental se efetive, as inovações poupadoras de energia e materiais necessitam se difundir por todas as atividades econômicas e conclui que o padrão tecnológico deve ser vantajoso para que a difusão alcance um comprovado aumento de eficiência.

O mesmo autor ainda informa que a Comunidade Europeia e o Japão conseguiram reduzir quantidades de emissões de energia entre os idos 70 e 80, demonstrando que é possível alterar as formas de produzir em direção a um considerado objetivo ambiental.

Uma iniciativa legítima e bem sucedida que é citada por Barbieri et al.(2010) é da empresa brasileira Native que produz alimentos orgânicos usando processos agrícolas e industriais compatíveis com os objetivos do desenvolvimento sustentável e de forma bastante rentável. Os autores também comentam que Norman Borlaug - pai da revolução verde e prêmio Nobel da Paz de 1970 - considerava a agricultura orgânica menos adequada ao meio ambiente, por ter menor produtividade e necessitar de mais áreas de lavoura para atender a 
mesma demanda por alimentos; no entanto, a alta produtividade da Native aliada ao intenso esforço de inovação em processo, produto, gestão e modelo de negócio conseguiu aliar benefícios ambientais, econômicos e melhoria de qualidade de vida dos trabalhadores, principalmente os que trabalham no corte da cana.

O estímulo às mudanças a partir do paradigma vigente pode se tornar uma tecnologia dominante e redirecionar as indústrias a um posicionamento com parâmetros ambientais.

\section{2- Perspectivas Ambientais}

\section{1- Inovação Ambiental}

O desempenho econômico está associado à competitividade principalmente quando a empresa ao formular e implantar com sucesso uma estratégia que cria valor (projeto dominante) e outras empresas não podem replicar com sucesso. É claro que o retorno deve compensar os esforços para que os investidores mantenham interesse nos negócios. A lucratividade é um dos pontos relativos aos negócios além dos riscos e os impactos que podem afetar a sociedade. Aliar a qualidade ambiental aos investimentos futuros traz a possibilidade de maximizar os lucros, não só no curto como no longo prazo, e legitima o contrato entre empresa e sociedade.

As decisões tomadas pelas firmas afetam a economia, logo a microeconomia e a sustentabilidade podem convergir ao aplicar a estratégia na condução dos negócios. Os estudos sobre gestão estratégica e competitividade podem ser vistos nos trabalhos de Prahalad e Hamel (1998) que expõe a necessidade da firma possuir competências essenciais como vantagem competitiva. Essas competências são para toda a firma, como aprendizado coletivo, e dessas competências, em certa medida, derivam os produtos essenciais que levam aos produtos finais que contribui para as economias de escala e de escopo.

O estudo sobre estratégias também pode ser visto em Porter (1998) através da estratégia corporativa da empresa diversificada e de seus quatro conceitos que são mecanismos que criam valor para o acionista, requer organização e gerenciamento de formas diferentes quando esta empresa define claramente seu papel e seus objetivos.

O objetivo claro de uma empresa pode ser a inovação. O conceito de inovação tem sido objeto de análise de diferentes linhas de pensamento. Segundo o Manual de Oslo, inovação "é a implementação de um produto (bem ou serviço) novo ou significativamente melhorado, ou um processo, ou um novo método de marketing, ou um novo método organizacional nas práticas de negócios, nas organizações do local de trabalho ou nas relações externas” (Barbieri,2010,p.151). Está associada ao sistema nacional de inovação, porém diversos autores acrescentam as diferenças regionais e locais.

A inovação, tratada por Schumpeter como principal dinamizadora da atividade econômica em um ambiente de constante evolução (Possas,1988), traz "um novo contexto de concorrência capitalista na qual as inovações verdes e os direcionamentos da sustentabilidade ambiental nas firmas poderão se tornar determinantes de vantagem competitiva por novas trajetórias tecnológicas” (PORTUGAL JUNIOR;FORNAZIER,2012,p.57).

Para Silva (2004,p.207), “a concorrência, alçada ao centro da análise, revela-se como o motor do processo incessante e endógeno de mutação” que leva à destruição criadora, a disputa entre as firmas mais pela sobrevivência no mercado do que pela própria maximização do lucro. 
Segundo Possas(2002,p.419): “A concorrência é um processo de criação de espaços e oportunidades econômicas [...] e implica o surgimento permanente e endógeno de diversidade no sistema econômico capitalista [...]. Importa mais a criação de diferenças por meio das inovações em sentido amplo".

Segundo Barbieri (2010) a inovação ambiental deve trazer benefício triplo (dimensões: econômica, social e ambiental) e a introdução (produção, assimilação ou exploração) de produtos, processos produtivos, métodos de gestão ou negócios, novos ou significativamente melhorados devem avançar em benefícios significativamente líquidos. Ainda segundo o autor (idem,p.151,152), nos textos sobre gestão da inovação encontra-se que "a expectativa de um resultado econômico negativo ou abaixo do esperado interrompe ou redireciona um processo específico de inovação. A interrupção ou redirecionamento do projeto também deveria ocorrer com respeito aos resultados sociais e ambientais negativos ou abaixo do esperado”.

Inovar é um conceito amplo que agrega todo um sistema nacional de inovação (conceito criado em 80 pelos economistas Richard Nelson e Christopher Freeman) e segundo seus criadores, esse sistema "é uma construção institucional, produto de uma ação planejada e consciente ou de um somatório de decisões não planejadas e desarticuladas, que impulsiona o progresso tecnológico em economias capitalistas complexas” (Barbieri,2010,p.153). São instituições que se articulam com o sistema educacional, industrial, empresarial e financeiro que geram, implantam e difundem inovações tecnológicas capazes de criar oportunidades, e é nesse contexto que a incorporação da sustentabilidade deve ser adequada.

Nesse sentido, Portugal Junior e Fornazier (2012) inferem que com a evolução do processo de concorrência capitalista e a necessidade de usufruir de forma consciente os recursos naturais, as perspectivas de desenvolvimento de tecnologias mais limpas e outras oportunidades inovacionais poderão capacitar as empresas a um processo de melhor gestão ambiental.

Os mesmos autores (idem,p.43) comentam que "dentro do conceito de paradigmas e trajetórias de Dosi percebe-se nitidamente a existência de um paradigma científico sobre os limites de uso dos recursos naturais do planeta determinando um novo paradigma tecnológico de produção que levará a várias trajetórias distintas de inovações ambientalmente corretas”.

As inovações ambientais buscam estabelecer uma vantagem competitiva e melhorar o desempenho com inovações de produtos e processos, redução de custos, novos mercados (Porter e Van der Linde,1995) e diante do caráter inovativo, dinâmico e concorrencial do capitalismo, as firmas que não se adaptarem ao novo paradigma podem ser excluídas desse processo em função da própria dinâmica que surge.

O mesmo autor destaca uma nova abordagem - Strategic Niche Management (SNM) que facilita a introdução e difusão de tecnologias sustentáveis por meio de nichos tecnológicos (experimentos).

Reydon et al.(2007) relatam que o aproveitamento de oportunidades pode resultar no aumento de competitividade das empresas. Portanto, políticas ambientais são necessárias, não existindo um modelo certo para incentivar a inovação, pois cada setor e cada país possuem realidades econômicas e institucionais diferentes. E concluem que o aumento da competitividade é resultado do desenvolvimento de inovações tecnológicas pelo aproveitamento de oportunidades nos métodos, produtos e processos. A tecnologia permite que, ao longo do tempo, outras inovações se produzam e se transformem também em 
oportunidades de mercado. E diante da lógica e da racionalidade trazer a inovação ambiental para o processo endógeno e dinâmico da mudança sociotécnica.

\section{2- Direcionamento Estratégico}

No processo de competitividade sistêmica outro posicionamento estratégico e também influenciado por questões ambientais é a política industrial voltada para a sustentabilidade que pode levar um segmento e/ou setor econômico de um país a obter vantagem competitiva, ampliando e fortalecendo sua posição de mercado como importante player mundial.

“Os países Suécia, Noruega e Finlândia desenvolveram profundas capacidades tecnológicas inovadoras em setores relacionados a recursos naturais como mineração, florestal, celulose e papel, óleo e gás” (FIGUEIREDO,2011apud PORTUGAL Jr.et al., 2012,p.897).

A diferença do Brasil de outros países do mundo é a sua imensa diversidade ambiental e diferenças ecológicas, a disponibilidade de recursos naturais que, se ambientalmente bem aproveitados, resultam em geração de riquezas e distribuição de renda. O potencial das florestas, a gestão de recursos hídricos, a correta valorização dos ecossistemas, podem se reverter em importantes fontes de renda e geração de empregos.

A importância de estabelecer a sustentabilidade ambiental como um direcionador estratégico via política econômica e industrial, segundo Portugal Jr. et al.(2012), é uma forma de reestabelecer a indústria nacional brasileira concomitante ao processo de antecipação de competitividade verde podendo resultar em liderança tecnológica e comercial em nível internacional.

Os mesmos autores enumeram benefícios e oportunidades para a economia brasileira ao estabelecer uma política industrial direcionada a um processo de reindustrialização sustentável:

- Possibilidade de crescimento do Valor de Transformação Industrial (VTI) por meio da indústria verde, dado o alto VTI de produtos como painéis solares fotovoltaicos, turbinas para geração de energia eólica, novos materiais e produtos e reestruturação das indústrias convencionais.

- Aumento da participação de modais energéticos renováveis conjugados com maior eficiência de utilização.

- Maior eficiência na indústria de construção civil por meio do uso de insumos minerais reciclados.

- Incorporação da questão ambiental nos programas de incentivo à inovação.

- Melhoria do acesso da indústria a materiais reciclados.

A Secretaria do Meio Ambiente do estado de SP indica vantagens potenciais com a Economia Verde e acrescenta que se fosse utilizada em âmbito nacional poderia trazer importantes benefícios ao país. Podem-se somar a isso, os incentivos fiscais e planos de infraestrutura.

\section{3- Atuação do Estado e Regulação Ambiental}

Habermas afirma que a regulamentação permanente do Estado a partir do século XIX surge como um mecanismo de defesa contra as disfunções geradas pelo sistema. As ações governamentais deixam de ser dirigidas para a realização de objetivos práticos e passam a ser pautadas por medidas que compensem a sociedade 
pelas disfunções e pelos riscos que ameaçam a própria integridade do sistema. Legislação trabalhista e ambiental, novos mecanismos de financiamento, ampliação dos sistemas de saúde são apenas alguns exemplos conhecidos da atuação do Estado visando preservar o equilíbrio do sistema (Demajorovic,2003,p.37).

É imperativo, pois, a atuação do Estado como indutor, regulador e como garantia de mercado na aplicação de instrumentos de políticas públicas em relação a questão ambiental. Necessária também a sua atuação como integrador de políticas ambientais no âmbito de políticas econômicas.

Portugal Jr. e Fornazier (2012,p.46) complementam: "Incorporar o Estado e as instituições como agentes no processo dinâmico do capitalismo e do surgimento e difusão das inovações é extremamente importante para se entender e internalizar as questões ambientais".

Para uma política eficaz de direcionamento ambiental é necessário que o Estado e as instituições conheçam a estrutura e a dinâmica das inovações e das mudanças tecnológicas para viabilizar ações que levem a consequências desejáveis ao meio ambiente. Essas ações poderão incentivar projetos dominantes com enfoque ambiental (Portugal Jr.;Fornazier,2012) que tenham características que o mercado espera e outros se veem compelidos a copiar e com o surgimento e a adoção do projeto dominante, o mercado se estimula ao processo de produção (Utterback,1994) e consequentemente a redução de impactos ambientais e/ou criação de novos produtos ambientais.

A presença do Estado é importante principalmente em países ou setores pouco desenvolvidos que precisam de impulso na economia e colaboração para a solução dos problemas ambientais através de alteração de tributos, eliminação de subsídios, educação ambiental, estruturação do marco legal, entre outros e em iniciativas de melhoria dos próprios órgãos governamentais (Exemplo: o Programa de Aquisições Sustentáveis do Ministério do Planejamento em 2008).

Para Porter e Linde (1995) a visão dicotômica entre meio ambiente e competitividade ainda resiste. No entanto, essa posição só seria aceita se fossem estáticos tecnologias, produtos, necessidades. Mas na atual dinâmica da inovação há inúmeras possibilidades de se desenvolver alternativas onde objetivos contraditórios (regulação x competitividade) se agregam.

Kemp et al. (2002 apud Kiperstok et al.,2002) afirmam que a regulação não desencadeia incentivos à inovação, "apenas a canaliza e modulam se constituindo em apenas uma entre muitas variáveis”. E complementa que os instrumentos que de alguma forma incentivam a inovação são as proibições de produtos, padrões de desempenho, instrumentos econômicos e acordos voluntários.

Para Kiperstok et al. (2002), do ponto de vista econômico, as empresas têm a capacidade de aprender a cumprir a legislação ambiental da forma mais eficiente possível e a isso se denomina curva ou processo de aprendizado. $\mathrm{O}$ autor cita outros autores que consideram os instrumentos econômicos mais vantajosos que a aplicação de medidas de comando e controle ou de fixação de padrões de desempenho e tecnológicos e comenta a existência de acordos voluntários e acordos negociados que podem se tornar difusores de inovação, tomadas de consciência coletiva que juntos com medidas legais eficientes propiciam a inovação em coerência com políticas ambientais.

Atuação Responsável é um exemplo de programa voluntário que a indústria química apresenta como nova forma de conduzir os negócios (mudança de cultura) com base em 
compromissos éticos com a sociedade. Na prática, busca melhorar a percepção do público em relação às formas de gerenciamento das unidades químicas (DEMAJOROVIC,2010).

\section{4- Mecanismos Indutores de Melhorias Ambientais}

Uma das condições necessárias para a devida atuação do Estado além da regulação (comando e controle) são os mecanismos de mercado (instrumentos econômicos) que em relação ao meio ambiente e no caso de um redirecionamento industrial sustentável devem ter mecanismos específicos que procuram manter as atividades econômicas dentro dos limites de utilização ecológica dos recursos naturais.

Com relação aos instrumentos econômicos sua escolha deve ser adaptada a cada caso podendo ter aplicação concomitante de dois ou mais instrumentos. Nesse caso o Estado deve esclarecer aos agentes a sua utilização e aplicabilidade.

Marcondes e Bacarji (2010) citam que nos anos 70, o setor público no papel de regulador do processo de desenvolvimento criou normas de 'comando e controle', entendendo que o impacto ambiental causado pelas empresas deveria ser pago por elas.

Porter e Linde(1995) já assinalavam que a legislação deveria criar incentivos à inovação empresarial para que a correção dê lugar a prevenção e que os setores mais competitivos estão preparados para aceitar a regulamentação ambiental como oportunidade de inovação.

Percebeu-se também que após o advento da lei 10.165/2000 (Política Nacional de Meio Ambiente - taxa de controle e fiscalização ambiental, 2000) empresas que possuem atividades potencialmente poluidoras e utilizadoras de recursos naturais têm indicador de responsabilidade ambiental superior. Ou seja, a existência do fator regulamentação tem efeito positivo para a responsabilidade ambiental.

O surgimento das normas ambientais está diretamente relacionado com a evolução das questões ambientais e seus impactos nas esferas comercial, econômica e política. A norma ISO 14001 voltada para a gestão ambiental determina os elementos para um sistema de gestão eficaz e tem por finalidade equilibrar a proteção ambiental e a prevenção da poluição com as necessidades socioeconômicas e é aplicável a todos os tipos e tamanhos de organização (Ribeiro Neto;Tavares;Hoffmann,2010).

Normas técnicas foram difundidas com bastante êxito não só com a finalidade de protecionismo comercial como também importantes direcionadores de vantagens competitivas das firmas indicando que nem sempre o mercado é o agente mais eficiente para permitir uma maior harmonia entre diversos interesses (Portugal Jr.;Fornazier,2012). Contudo, os sistemas de gestão ambiental implantados nas empresas, que tornaram mais eficientes a gestão empresarial, é um meio de se atingir os resultados e não um fim em si mesmo e se mostram mais eficazes quando atrelados a políticas, programas e procedimentos.

Diversos outros mecanismos, nacionais e internacionais, fazem parte do universo de estudo e ação sobre o meio ambiente. Podem ser citados: rotulagem ambiental, selos verdes (os dois criados com base em análise do ciclo de vida do produto), gestão participativa, responsabilidade socioambiental, ecoinovação (ecoinovação refere-se a ecoeficiência que concilia eficiência econômica e melhoria do desempenho ambiental - menor uso dos recursos e diminuição de resíduos e poluentes), ecologia industrial (relacionamento entre sistemas industriais e atividades econômicas com os sistemas naturais), cada um com suas 
especificidades, que orientam os agentes econômicos a introduzirem mudanças em sua cadeia produtiva para atingir um nível ponderado de melhoria ambiental.

\section{Conclusão}

Diante de todo o conteúdo exposto anteriormente, entende-se ser de curto prazo as ações necessárias para serem reexaminados e redimensionados os projetos de crescimento econômico sob a perspectiva do desenvolvimento humano e da conservação ambiental.

Nesse contexto, as empresas tiveram que ser repensadas e novos termos como meio ambiente, responsabilidade socioambiental e aprendizado contínuo foram incorporados ao dia-a-dia dos gerentes empresariais, dos países e da sociedade. Novos grupos e novos atores estão influenciando novas atitudes e exigindo novas decisões em que os debates sobre a questão ambiental se tornam irreversível e generalizado.

Contudo, diversas empresas entenderam que a relevância de critérios ambientais pode se transformar em retorno financeiro atrativo e competitividade e redefiniram suas estratégias integrando-as à inovação, que como foi visto, é uma importante ferramenta no processo de concorrência. A elevação da produtividade dos recursos e o reposicionamento em novos mercados podem ser utilizados para ganhos ambientais.

Os riscos advindos dos impactos ambientais se transformaram em novas e promissoras oportunidades de negócios a partir de 1990. Investimentos para o controle da poluição, para melhoria da segurança nos processos e para indústria ecológica dinamizaram a moderna economia capitalista.

É imprescindível, conforme Freeman, que a incorporação de objetivos ambientais se integre às novas tecnologias e se difunda por todo o sistema econômico e seja consistente com a prioridade ambiental. O autor considera ainda que "se está no meio de uma crise de ajustamento estrutural e que as formas embrionárias do próximo paradigma tecnológico já estejam atuando e é provável que dentro de duas ou três décadas a aplicação de inovações ambientais venha a ser dominante”.

\section{Referências}

BARBIERI,J. et al. Inovação e Sustentabilidade: Novos Modelos e Proposições. RAE. São Paulo. v. 50. n. 2. abr./jun. 2010 .

BARBOSA,P. Índice de Sustentabilidade Empresarial da Bolsa de Valores de São Paulo (ISE/BOVESPA). 2007. 150f. Dissertação (Mestrado em Administração) - Instituto COPPEAD de Administração, UFRJ, 2007.

DEMAJOROVIC,J. Sociedade de Risco e Responsabilidade Socioambiental - Perspectivas para a educação corporativa. São Paulo: Editora Senac. SP,2003.

DEMAJOROVIC,J.;VILELA Jr.,A.(orgs.) Modelos e Ferramentas de Gestão Ambiental desafios e perspectivas para as organizações.São Paulo:Editora Senac.2 ${ }^{\mathrm{a}}$ ediç̧ão.2010.

EPELBAUM,M. A Influência da Gestão Ambiental na Competitividade e no Sucesso Empresarial. 2004. 190f. Dissertação (Mestrado em Engenharia da Produção) - Escola Politécnica da USP, São Paulo, 2004. 
FIGUEIREDO,P.N. O Papel dos Recursos Naturais no Crescimento do País. Conjuntura Econômica, Rio de Janeiro, v.65,n.7,p.46-48,jul.2011.

FREEMAN,C. The Economics of Hope: essays on technical change, economic growth and the environment. London; New York:Pinter Publishers, 1992.

KEMP,R. Technology and environment policy: Innovation effects of past policies and suggestions for improvement. In: Innovation and the environment. 1st ed. Vol. 1. (Ed:OECD) OECD, Paris, 35-61. 2000.

KIPERSTOK,A. et al. Inovação como Requisito do Desenvolvimento Sustentável. REAd Edição Especial 30 Vol. 8 No.6, nov-dez 2002.

MARCONDES,A.;BACARJI,C. ISE: Sustentabilidade no Mercado de Capitais 2010. São Paulo: Report Editora, 2010.

MINISTÉRIO DO MEIO AMBIENTE Política Nacional do Meio Ambiente. Disponível em $<$ http://www.mma.gov.br/port/conama/>. Acesso em jan.2016.

NETO,F.;SILVA FILHO,J.;OLIVEIRA,J.GURGEL,L. A Gestão Ambiental como resultado de tempos de mudança: uma proposta de aperfeiçoamento do conceito de proatividade ambiental. XIII ENGEMA: Inovação e Sustentabilidade: as novas fronteiras da Gestão Empresarial, FGV/EAESP SP, dez. 2011.

PORTER.M; Da Vantagem Competitiva à Estratégia Comparativa in MONTGOMERY,C e PORTER,M Estratégia: a busca da vantagem comparativa - (org.) Ed. Campus. 6a edição.1998.

PORTER,M.;VAN DER LINDE,C. Green and Competitive: ending the stalemate. Harvard Business Review, spt.-oct., 1995, p.122-134, 1995.

PORTER,M.;VAN DER LINDE,C. Towards a New Conception of EnvironmentalCompetitiviness Relationship. Journal of Economic Perspective,9(4), Saint Paul,1995.

PORTUGAL JUNIOR,P.;FORNAZIER,A. Fatores Indutores de Inovações Verdes nas Firmas: notas para uma convergência entre a concepção neo-schumpeteriana e a ação efetiva do Estado. Leituras de Economia Política, Campinas,(20),p.37-60,jul.2012.

PORTUGAL Jr.,P.;PORTUGAL,N. Microeconomia e Meio Ambiente : Análise de Fundamentos Microeconômicos inerentes à Gestão Ambiental nas Organizações. Rev. Adm. UFSM, Santa Maria, v. 3, n. 3, p. 393-410, set./dez. 2010.

PORTUGAL Jr.,P.;REYDON,B.;PORTUGAL,N. A Sustentabilidade ambiental como direcionador estratégico ao processo de reindustrialização no Brasil. Economia e Sociedade, Campinas,v.21,Número especial,p.889-907,dez.2012.

POSSAS,M. Em Direção a um Paradigma Microdinâmico: a abordagem neo-schumpeteriana. In: Ensaios sobre Economia Política Moderna: Teoria e história do pensamento econômico. p.157-177.1988.

POSSAS,M. Concorrência Schumpeteriana. In: Kupfer \& Hasencliver (org.). Economia Industrial, RJ: Campus,2002. 
PRAHALAD,C.;HAMEL,G. A Competência Essencial da Corporação. In: MONTGOMERY,C.;PORTER,M. E. Estratégia: a busca da vantagem competitiva. Rio de Janeiro: Campus, 1998.

REYDON,B.;CAVINI,R.;ESCOBAR,H.;FARIA,H. A Competitividade Verde enquanto estratégia empresarial resolve o problema ambiental? Texto para discussão. IE/UNICAMP.n.125,jun.2007. ISSN 0103-9466.

RIBEIRO NETO,J.;TAVARES,J.;HOFFMANN,S. Sistemas de Gestão Integrados. São Paulo: Editora SENAC SP,2010.

SALVIANO,R. Economia do meio ambiente: Desenvolvimento sustentável através de um novo paradigma, um estudo de caso. 2004. 55f. Trabalho de conclusão de curso (graduação) UNICAMP, Campinas SP, 2004. Disponível em

<http://www.bibliotecadigital.unicamp.br/document>. Acesso em jan. 2016.

SANTOS,P.;FINAZZI,S. Análise do discurso ambiental dos bancos brasileiros de varejo cujas ações são negociadas na BOVESPA. IV Encontro Nacional da ANPPAS, jun. 2008. Brasília DF, 2008.

SILVA, A.L. Concorrência sob Condições Oligopolísticas: contribuição das análises centradas no grau de atomização/concentração dos mercados. Campinas: Unicamp. IE,2004. (Coleção Teses).

UTTERBACK,J. Dominando a Dinâmica da Inovação. Rio de Janeiro: Qualitymark,1994. 